\title{
Why Do Korean Listeners Have Difficulty Recovering the Meaning of Casual Speech in English? A Study in Pragmatics
}

\author{
Jiyon Cook $^{1}$ \\ ${ }^{1}$ Department of English Language and Literature, Sejong University, Seoul, Korea \\ Correspondence: Prof. Jiyon Cook, Department of English Language and Literature, Sejong University, 98 \\ Gunja-dong, Gwangin-gu, Seoul 143-747, Korea. Tel: 82-2-3408-3630. E-mail: jycook21@sejong.ac.kr
}

Received: January 25, $2012 \quad$ Accepted: February 22, $2012 \quad$ Published: May 1, 2012
doi:10.5539/ass.v8n6p40
URL: http://dx.doi.org/10.5539/ass.v8n6p40

\begin{abstract}
This paper pragmatically explores why Korean listeners encounter difficulties in recovering the speaker's meaning during casual English conversations. Meaning is derived not only from the simple decoding of the composed words but also through a more complex cognitive-pragmatic process of "free enrichment." In addition to enriching a linguistically encoded logical form, deriving meaning necessitates the recognition of different uses of a language, one of which is the use of expressions in the listener's culture. The differences in the perception of utterances between native and non-native English speakers highlight the influence of metapragmatic awareness on free enrichment. It can elaborate and/or repair a propositional attitude alongside a linguistically encoded logical form as well as determine an explicature or implicature. This study finds that the need to be aware of the uses of the target language imposes a more conscious burden on Korean listeners, leading to difficulties in recovering the speaker's meaning.
\end{abstract}

Keywords: speaker's meaning, linguistic underdeterminacy, pragmatic enrichment, relevance, metapragmatic awareness, explicature, higher-level explicature, implicature

\section{Introduction}

During a conversation, the listener derives meaning from both decoding the linguistic expression and inferring from the context (see Sperber and Wilson 1986, 1995). The processes involved in arriving at the intended meaning are referred to as pragmatic inference and account for the specification of encoded and, more often, the unencoded constituents of utterance. Pragmatics is primarily concerned with how people understand utterances. It examines how the listener grasps the meaning that is being communicated. Past research has focused on how listeners infer utterance meaning in the Gricean tradition (see Grice 1975; Horn 1989; Levinson 1983, 2000, etc). These studies typically examine certain pragmatic principles and explore how meaning is communicated in accordance with or in violation of one of those principles. Other studies, based on the relevance-theoretic view of cognition and communication, examine interpretation of utterances as the unavoidable consequence of searching for cognitive effects of the smallest processing effort (see Sperber and Wilson 1986, 1995; Blakemore 1992; Carston 2002).

Traditionally, utterance meaning has been categorized as "what is said" and "what is implicated." The speaker's meaning is viewed as "what is implicated," and this view has been widely used in implicature-based research (see neo-Gricean work). However, within cognitive pragmatics, the speaker's meaning is considered to include explicitly communicated meaning (explicature), implicitly communicated meaning (implicature), and context. Here, the content of the speaker's utterance (referred to as "explicature" in Sperber and Wilson (1986)) extends beyond Grice's conception of "what is said," and understanding this utterance involves pragmatic processes such as enrichment, saturation, ad-hoc concept construction, reference assignment, and disambiguation (see Recanati 1991; Bach 1994; Sperber and Wilson 1986/1995; Carston 1988/2002) According to Carston (2004, p. 819), “a key feature in the derivation of an explicature is that it may require 'free' enrichment; that is, the incorporation of conceptual material that is wholly pragmatically inferred, on the basis of considerations of rational communicative behavior, as these reflect relevance-theoretic account of human cognitive functioning." Enrichment is cognitive inference that adds context-based meaning where the linguistic expression is used to decode the meaning. It is best described by examples from Carston (2004, p. 830): 
(1) a. It'll take time for your knee to heal.

b. Ralph drinks.

c. Emily has a temperature.

These expressions are semantically complete, but the speaker does not intend to express an obvious, uninformative proposition. The sentences explicitly communicate the following, respectively:

(2) a. It'll take quite a long time for your knee to heal.

b. Ralph drinks alcohol (habitually).

c. Emily has a high temperature.

As Carston (2004, pp. 830-839) states, what the speaker says (=explicature) is the enriched proposition ("developments of logical form") as in (2). These assumptions are automatically ("unconsciously") recovered by native English speakers with "the presumption of relevance and accessible contextual assumptions" (2004, p. 830). That is, the basic explicatures (communicated propositions) in (2) are pragmatically accounted for. However, Carson's enriched proposition does not explain the derivation of explicature of utterances by nonnative listeners. Nonnative listeners may not be as adept at recovering the meaning of these utterances as native speakers, for whom the process is unconscious. To better understand this gap in meaning derivation between native and nonnative speakers, I examine the difficulties faced by Korean listeners, in recovering the speaker's meaning during casual English conversations.

Korean listeners have been observed to encounter difficulties in recovering the meaning of casual English utterances, as reported for a group of Korean university students aged 22-27 years (Note 1). To explore the reasons behind these issues, this study analyzes the meaning of explicit constructions from the perspective of Korean listeners. It also focuses on problems in understanding that stem from the conflicting differences in the use of the Korean language and English. Consider the following exchange between two speakers of different nationalities:

(3) A: That book looks like a Korean fairytale.

B: You're right.

(4) A: We'll have to charge you for this service.

B: You're kidding.

The explicit meaning (explicature) of (3B) is easily recovered by Korean listeners: the communicated proposition is You're correct and the propositional attitude suggests that B intends to agree with A. In the case of (3B), the process of identifying the speaker's meaning is almost identical between native English listeners and Korean listeners. However, unlike with the underlined utterance in (3), Korean listeners find it difficult to correctly recover the explicature of (4B). This is because the speaker in (4B) is not communicating a propositional content but expressing his frustration. Of course, neither Korean listeners nor native English listeners consider the explicature of (4B) to be You're lying. Some kind of inference at a different level seems to influence the interpretation of (4B).

The existing literature on relevance-based pragmatics does not offer detailed explanations on how propositional attitudes (higher level explicatures) can be recovered. Sentences such as (4B) highlight that sometimes listeners have to go beyond understanding the explicature of an utterance, which is typically achieved by resorting to the cognitive process called "enrichment," proposed by relevance theorists (Note 2). Native speakers are accustomed to using the expression "You are kidding." In contrast, nonnative speakers lack the intuitive ability to interpret the linguistically encoded logical form of the utterance; they possibly interpret the utterance because they have learned this expression in class. This difference in the learning background of the listeners may have an influence on their perception of the expression. In fact, most nonnative speakers of English may encounter such difficulties; this problem is not specific to Korean listeners or to the intricacies of the Korean language. The differences in enrichment process between native and nonnative speakers can be attributed to their cultural orientation.

To better explain the challenges faced by non-native speakers of English, such as Koreans, the notion of enrichment should be extended to deal with the following: identifying the explicature of an utterance (e.g., (4B)), recovering the differently constructed meanings of an utterance by different listeners, and recovering an utterance with multiple explicatures. In this paper, I have adopted an approach that is based on the relevance theory, which is used to explain utterance understanding (e.g., Sperber and Wilson 1986, 1995; Blakemore 1992; 
Carston 2002; Wilson and Sperber 2004). I argue that metapragmatic considerations enrich a linguistically encoded element and aid in the recovery of a higher-level explicature. Thus, metapragmatic awareness is a significant factor that prevents Koreans from recovering an English speaker's meaning.

This paper is organized as follows. Section 2 discusses linguistic underdeterminacy and the spectrum of the speaker's meaning in casual speech. Section 3 illustrates the metapragmatic intrusions in the construction of an explicature. Section 4 extends the concepts of enrichment and the comprehension process. Finally, Section 5 summarizes the difficulties faced by Korean listeners in recovering an English speaker's meaning.

\section{Linguistic Underdeterminacy, Enrichment, and the Speaker's Meaning}

Linguistic expressions are underspecified because they cannot fully accommodate thoughts/assumptions; pragmatic inference on the part of the listener is needed to arrive at the communicated assumption (Recanati 1991; Carston 2002, etc.). Carston (2002) calls this the linguistic underdeterminacy thesis. According to the thesis, "the meaning encoded in the linguistic expressions used, the relatively stable meanings in a linguistic system, and meanings that are widely shared across a community of users of the system underdetermine the proposition expressed (what is said). The hearer has to undertake processes of pragmatic inference in order to work out not only what the speaker is implicating but also what proposition she is directly expressing" (Carston, 2002, pp. 19-20) (Note 3). In fact, the same expressions can communicate different assumptions. For instance:

(5) A: Daddy, can I come home little late?

B: Where are you?

When a father answers a call from his daughter who has not yet come home, the explicature of the underlined utterance in the exchange is recovered as (6).

(6) I am asking where you (=his daughter) are now.

The italicized parts are unconsciously (automatically) inferred. Consider another exchange (Note 4).

$\mathrm{M}$ : Hi, professor. I have a question about what you were discussing in class today.

W: You mean the stuff on sand dunes?

M: Yes. I didn't understand your explanation about how sand dunes form. I mean, I don't really have the saltation process down pat.

W: Here, let me show you from the book... OK, it says here that in the saltation process, the wind lifts individual sand grains into the air...

M: Just a moment, professor, where are you? (p. 467)

In the above exchange, by "where are you," the speaker means:

(8) What part are you explaining?

This assumption is explicitly communicated and any listener, irrespective of nationality, will understand the above to be the speaker's meaning. Also, if the student has a copy of the book, then it is possible that the speaker means "Which page are you reading from?"

Consider another exchange:

M: I finished correcting your test paper, and I'm sorry to say that you failed the test. I'm not really sure what you found so difficult.

W: I had trouble understanding some of it.

M: There's one question on the test which I believe you completely misunderstood. Why don't you take out your textbook and let's discuss it. That's page $245 \ldots$ number fourteen.

W: Uh, OK... when two bacteria exchange genetic information, what is the process called? Uh... I believe the answer is..

M: Marilyn....where are you? (p. 470) (Note 5)

What does the speaker intend to express by the underlined part? The first assumption that comes to mind is (10).

(10) I don't think you're looking at the right page.

(10) is implicitly communicated and derived by the listener, regardless of his or her nationality. The listeners know that the underlined utterances in (7) and (9) do not communicate $I$ do not know where you are. The content of (6), (8), and (10) can be recovered from the linguistic expressions used and the context. These assumptions are 
pragmatically enriched in the search for relevance, and they are known to be the relevant ones that do not require additional unnecessary processing effort by the listeners.

The process of deriving the speaker's meaning is different between native and nonnative speakers. It actually depends on the degree of relevance that is most likely to have cognitive effects on the listener at that moment in that context. For instance, in (5), speaker A (daughter) may not recover the explicature presented in (6). Instead, she may derive the implicature You must come home right away as her father's meaning. Similarly, the explicit meaning of the underlined utterance (9) is What page are you looking at; it is not the same as the speaker's meaning in (6). Although what the speaker says in (9) is \{What page are you looking at?\}, it is the implicature $<I$ don't think you're looking at the right page $>$ that is identified as the intended meaning (Note 6). In other words, the professor's interest lies in highlighting Marilyn's mistake, rather than knowing the page that she is looking at.

\section{Metapragmatic Intrusion in Inferring the Speaker's Meaning}

Listeners use the relationship between speakers and the role of the speaker and the listener as cues to construct the meaning of an utterance as well as judge the intended meaning (basic explicature, higher-level explicature, or implicature). Therefore, the communicated meaning of "Where are you?" in (7) can be (10); however, (8) is more readily inferred by Korean listeners because a student (the speaker) is unlikely to expect her professor (the listener) to be looking at the wrong page. In case the student is asking the professor to share the page number, (10) may be possible, but (8) is more likely to be inferred.

Sometimes, knowing the reasons for a speaker's utterances is necessary to understand their meaning. The absence of this knowledge can make the listeners less accessible to the speaker's meaning. Consider the following example. A Korean student saw the phrase "Get stuffed" displayed in an advertisement on a double-decker bus in London, and she asked her English professor its meaning. The professor said (Note 7):

(11) Professor: Oh, can you see the picture of a pizza next to the phrase? (The student had not noticed the small picture of a pizza next to it). In this case, "Get stuffed" means "buy this stuffed crust pizza." But "Get stuffed" has multiple meanings. One meaning is an extremely harsh insult, which commands the listener to go away. If you tell your boss to get stuffed, it has a very bad meaning. When I saw this advertisement, it made me laugh; I guess it's not that funny, so here's my point.

A Korean listener can interpret the underlined utterance in different ways. A few possible interpretations are as follows:
a. The professor wants the students to understand her joke.
b. The professor does not think that her students have understood her joke.
c. The professor realizes that the students do not have a sense of humor.
d. The professor wants the students to focus on the topic.

However, in reality, (12a)-(12c) are rather removed from the intended meaning. Through the underlined utterance in (11), the speaker intends to direct the student's attention back to the main topic of discussion, as in (12d).

A native listener can automatically recover (12d) as the intended meaning; however, some Korean listeners are likely to infer (12b) or (12c). This is because it is highly unusual for a professor to use the phrase "it's not that funny" while reflecting on her own thoughts in a Korean classroom setting, which is exclusively meant for exchange of serious academic information. Such a phrase may be used in a personal conversation during a break or after class. However, when used in a classroom, students may accept it as conveying a propositional content and interpret it as the professor's remark on their lack of humor.

Carston (2002, p. 124) offers a broader definition of explicature than Sperber and Wilson (1995): “An assumption (proposition) communicated by an utterance is an 'explicature' of the utterance if and only if it is a development of (a) a linguistically encoded logical form of the utterance, or of (b) a sentential subpart of a logical form." According to Carston's (2002) definition of explicature, the possible explicit assumptions of the underlined utterance in (11) are as follows:

Basic explicature:

a. I guess what I'm saying is not that funny, so now here's my point. (development of linguistically encoded logical form) 
b. I guess what I'm saying is not that funny. (development of sentential subpart of a logical form)

c. So now here's my point. (development of sentential subpart of a logical form)

Higher-level explicature:

d. The speaker is saying (a) (development of linguistically encoded logical form)

e. The speaker is saying (b) (development of sentential subpart of a logical form)

$\mathrm{f}$. The speaker is saying (c) (development of sentential subpart of a logical form)

g. The speaker believes (a) (development of linguistically encoded logical form)

h. The speaker believes (b) (development of sentential subpart of a logical form)

i. The speaker believes (c) (development of sentential subpart of a logical form)

The assumptions (13a), (13d), and (13g) are the explicatures of the underlined utterance in (11), in accordance with clause (a) of Carston's definition. On the other hand, in accordance with clause (b) of the definition, the explicatures of the underlined utterance in (11) can be (13b), (13c), (13e), (13f), (13h), and (13i). The listener will not recover all of them. The actual explicature of the underlined utterance in (11) is contained in the sub-part of the utterance ("here is my point") rather than the first part ("I guess it's not that funny"). So how does the native listener recover (13c), and not (13a) or (13b)?

Although relevance theorists argue that the context offers cues to solving linguistic underdeterminacy, choosing (13c) and (13i) requires not only context but also knowledge of the specialized use of the target language. This specialized use or metapragmatic awareness seems to guide the listener to focus on (13c) and recover (12d) as the intended meaning, excluding all other possible meanings. In order to focus on (13c) instead of (13b), the listener has to be highly aware of the speaker's intention. This is possible if the listener is familiar with the teacher's manner of speaking or achieves mastery over the target language, similar to the level attained by a teacher of the language.

In general, it is believed that the speaker, aiming at relevance, communicates to the best of his or her ability and according to his or her preference (Sperber and Wilson 1995:270). However, to accurately recover the speaker's meaning, listeners should be knowledgeable of the speaker's (in this case, the professor's) speaking style, which is essentially awareness at a metapragmatic level. Linguistic behavior is governed by social norms that enable people to manipulate language according to their role, topic of conversation, and situation (Gumperz, 1982, p. 165). For instance, teachers use figurative language as an easy and interesting strategy to improve their students' understanding. If they find that their style of explanation is not being effectively assimilated by their students, they use figurative utterances to display their metapragmatic awareness (Note 8). In (11), the professor, who is aware of the effect of language, is reflecting on her own utterances.

Listeners who are able to perceive this, understand the reasons behind it, and are familiar with the professor's style of speaking English within the classroom can recover explicature (13i), from among the other assumptions (Note 9). This can be represented as follows:

(14) THE SPEAKER KNOWS HOW SHE IS USING LANGUAGE TO DO HER JOB, AND IS SAYING that her comparison is not adequately amusing to the students TO ATTRACT AND RETAIN THEIR ATTENTION, and SHE BELIEVES THAT IT IS BETTER TO go to the main part.

The capitalized parts represent higher-level explicatures and the boldfaced and underlined parts are metapragmatically recovered assumptions. The italicized parts represent the basic explicature. The assumptions in bold are derived at a conscious and interpersonal level. They do not form the unconscious and cognitive interpretation of the utterance. That is, the bold parts are not developments of the logical form and are not derived from a pure cognitive process of recovering conceptual content, which is required to produce cognitive effects (i.e., to be relevant) (Note 10). Without knowing the speaker's purpose, the listener may think that the professor is trying to amuse the students by cracking a joke.

\section{Enrichment Based on the Listener's Culture}

A listener's level of language use determines his or her process of enriching the linguistically encoded logical form and recovering meaning. In this section, we will discuss two kinds of enrichment involved in recovering the speaker's meaning: (i) repairing and (ii) elaborating. 


\subsection{Repairing an Unintended Inference}

Gaps in enriching the linguistically encoded logical form and the propositional attitude between native and non-native English speakers tend to cause misunderstanding in verbal communication. This can be attributed to the pragmatically different meanings that stem from the use of language in different cultures (Note 11). When listeners encounter an unusual use of the language and the decoded meaning refers to an undesirable explicature or implicature, they sometimes repair both the linguistically encoded meaning and the propositional attitude or, in some cases, just one of them. Let us refer back to example (2).

$$
\begin{aligned}
& \text { A: We'll have to charge you for this service. } \\
& \text { B: You're kidding. }
\end{aligned}
$$

The probable communicated assumptions of (15B) are as follows:
a. You're not serious.
b. You're lying.
c. Speaker B indicates his dismay.
d. Speaker B suggests that he doesn't believe speaker A.
e. Speaker B emphasizes his confusion.
f. Speaker B indicates that he is amused by the situation.

(16c) is an easily recoverable assumption for a native speaker. Neither native English speakers nor Korean listeners would infer that B intends to assert that $\mathrm{A}$ is lying. The native listener, however, would infer that B is expressing his feelings of dismay. On the other hand, Korean listeners may encounter difficulties in recovering the meaning of (15B). I asked 40 students in my General English class what they thought about the meaning of (15B). None of the 40 university students chose (16c) as the speaker's meaning; 32 of them chose (16a) and 3 chose (16f). They are most likely to automatically infer (16a) or (16d) as the speaker's meanings. The former is semantically enriched, while the latter is pragmatically enriched (Note 12). Why is (16c) not derived initially? This begs the question whether the two kinds of enrichment (semantic/pragmatic) fully account for deriving the explicit meaning.

(16a) and (16d) are not viewed as intended meanings by native speakers but are recoverable as intended meanings by Korean listeners. The assumptions (16a) and (16d) are known to Koreans who have learned the meaning of "You're kidding" in class. For an ordinary student with an intermediate level of English knowledge, (16c) is not a recoverable assumption as most students are not familiar with the usage of such expressions at this level (Note 13).

It is difficult for a Korean listener to view (15B) as a simple emotional expression. Phrases such as "You're kidding" are not often used in public in the Korean culture. Koreans are taught to reserve the use of such phrases for listeners who are extremely close associates or for whom the speaker has absolutely no regard. Owing to the rude connotations of the utterance, Korean speakers refrain from uttering "You're kidding" in public even if they want to share their negative evaluation of the listener. Such a phrase is usually interpreted as the speaker's dissatisfaction with the listener's behavior and can adversely affect the interpersonal relationship between the speaker and the listener.

If a speaker utters "You're kidding" in Korean to listeners and when hearing "you're kidding," Korean listeners will ask themselves "Did he really say I am kidding?" and feel unpleasant. Although the native speaker does not intend it as a personal insult and it may have meant nothing to the listener personally, a Korean listener can interpret it in this manner. Although most native among native listeners may not bother dwelling on the utterance nobody bothers to think about otherwise, for Korean listeners it is less of a monologue than a statement. Thus, even if a native speaker is unaware of uttering it ("you're kidding"), Korean listeners may initiate the comprehension process of the utterance (Note 14). Korean listeners initially interpret (15B) as:

(17) The speaker is telling me I am kidding.

On the other hand, a listener who tries to understand typical utterances in the speaker's culture may find that the expression "you're kidding" is commonly used by English speakers, especially if they are at a loss for words or when they want to express disappointment over an unexpected situation. In other words, (15B) can be uttered by a speaker to express his or her frustration, and not to the listener. This assumption would be represented as follows:
a. I am telling myself that it is disappointing.
b. You never know my feelings.
c. Oh my god!
d. It does not make sense. 
Once the listener learns that English speakers tend to express their feelings in this way (which is uncommon in Korean) and that (15B) can be used as an emotional response, they realize that the speaker does not wish to communicate a propositional meaning, such as (16a), or a propositional attitude, such as (16d), which are typically inferred by Koreans.

Korean listeners who are accessible to (18), which is a different use of the expression "you're kidding" in Korean, recognize that the English speaker is not passing a personal comment. They can repair the linguistically encoded meaning of (15B) from (16a) or (16d) to (16c). The listener, with this kind of inference, will be able to identify (16c) as the speaker's meaning, and not (16a) or (16d). Accordingly, they may translate (15B) as something along the lines of "Gleorsuga (그럴 수가)" or "Jeongmaryo? (정말요?)" instead of literal translations such as "Jangnanhae? (장난해?)" which was first recovered as sounding unpleasant. Repairing is specifically concerned with metapragmatic phenomena at a conscious level. Hence, it adds to the difficulties in recovering the speaker's meaning.

The listener who is aware of how the English expression, "you're kidding," is used can reply to the speaker by saying something like (19) but not (20):

(19) A: We'll have to charge you for this service.

B: You are kidding.

A: I am sorry. But you should pay.

A: We'll have to charge you for this service.

B: You are kidding.

A: No, I am serious. I'm not joking.

(19A) reflects the listener's understanding of B's intended meaning and feelings, whereas (20A) reflects an interpretation that is based on the usage of language in Korean culture and the listener's learning experience (Note 15).

The comprehension process of (15B) is shown in Table 1.

Table 1. The comprehension process of (15B)

Utterance: "You're kidding"

\begin{tabular}{|c|c|c|}
\hline Listener & Korean Speaker & Native English Speaker \\
\hline Semantic enrichment & (a) $\{$ You're not serious. $\}$ & NA \\
\hline Pragmatic enrichment & $\begin{array}{l}\text { (b) }\{\text { The speaker does not believe } \\
\text { the listener is serious. }\end{array}$ & NA \\
\hline Explicature 1 & (a) and (b) & NA \\
\hline Implicature 1 & (c) $<$ I am angry with you. $>$ & Not derived \\
\hline \multirow[t]{2}{*}{ Metapragmatic intrusion } & $\begin{array}{l}\text { The utterance is not an appropriate } \\
\text { way of speaking }\end{array}$ & Not arisen \\
\hline & Repairing (by Korean listener) & Repairing NA \\
\hline $\begin{array}{l}\text { Metapragmatic enrichment (by } \\
\text { the listener who is aware of the } \\
\text { usage in the target language) }\end{array}$ & $\begin{array}{l}\text { The speaker is expressing his } \\
\text { emotions to himself }\end{array}$ & NA \\
\hline Explicature 2 & $\begin{array}{l}\text { (d) }\{\text { The speaker is frustrated } \\
\text { because he has to pay the fee for } \\
\text { the service, which he would not } \\
\text { usually pay for.\} }\end{array}$ & $=($ via pragmatic enrichment $)$ \\
\hline Implicature 2 & $\begin{array}{l}\text { (e) }<\text { I do not want to pay the fee. } \\
>\end{array}$ & $=$ \\
\hline Speaker's meaning & (d) or (e) & $=$ \\
\hline
\end{tabular}


In sum, in the case of (15B), the communicated proposition recovered first is considered inappropriate in Korean culture. It is repaired after considering the usage of the expression in the target culture. This helps the listener derive the speaker's meaning. The communicated propositions (a) and (b) in Table 1 are the basic explicatures of the utterance, but they do not represent the explicit meanings for native speakers. Native speakers automatically derive the higher-level explicature (d), which plays a role in arriving at the implicature (e) in Table 1. Caution is essential for enriching the linguistically encoded element in a foreign language and for determining the speaker's meaning. However, despite caution, the scope for misunderstanding cannot be eliminated, especially if the decoded meaning is inappropriate in the listener's culture (Note 16).

\subsection{Elaborating on an Intended Inference}

The linguistically encoded meaning is enriched as a result of understanding the speaker's metapragmatic awareness and is developed partly from the assumptions based on the listener's cultural context. The following example shows that when the communicated attitude is perceived as polite, it is more likely to be fully elaborated to infer the intended meaning. Consider the following exchange.

(21) A: I don't know if some other students have made this request or if I'm the first... and I don't know how you would feel about this... but is it possible for me to make the film in my parents' neighborhood? Maybe I'm asking for too much, but before you say anything, could I just explain why?

B: Go right ahead. (p. 521)

When A utters the underlined part, the listener knows what the speaker means:

(22) The speaker thinks her question might be inappropriate.

This assumption is easily recovered by native listeners and Korean listeners alike. The Korean listener is familiar with this use of the language. The style of speech employed by the student (circuitous and with hesitation) and the professor are well known to the Korean speaker. In fact, some British listeners require additional linguistic encoding to interpret the speaker's intention from the underlined part. They can easily derive (22) only if the underlined part is extended to include the next sentence, "and I don't know how you would feel about this" and the other part, "Maybe I'm asking for too much." However, they usually recover (22) without too much trouble. Some Korean listeners tend to skip the utterances quoted above; however, some listeners require these because the first underlined utterance is not enough for them to detect the speaker's attitude.

The listener who knows this can access an assumption such as (23):

(23) The speaker knows her choice and use of words and is concerned about speaking in an appropriate fashion to avoid jeopardizing the relationship with the listener.

In order to fully grasp the speaker's meaning, the listener sometimes needs to know why something is being said. The underlined part of (21) shows metapragmatic awareness: the speaker is conscious of herself and her speech. Her utterance indicates that she does not wish to make anyone feel uncomfortable (Note 17). Listeners who do not perceive this to be the speaker's motivation can focus on the propositional content (rather than social meaning) and derive different assumptions. For example:

a. She wants to be the first student to ask the professor.

b. She thinks that other students may have made this request.

c. She expects her request to be approved by the professor.

(24a) and (24b) are not intended by the speaker, although (24c) can be one of the implicatures of (21).

However, to the Korean listener, (21) is automatically processed as a type of pre-utterance. The Korean listener will then proceed to the next utterance, as they usually do not focus on identifying the basic explicature (proposition) of the utterance in this case. For Korean listeners, initiating the inferential process of higher-level explicature is more important than recovering the proposition of the underlined utterance because recognizing the speaker's attitude is often crucial to Koreans. If the attitude expressed by the speaker is found to be impolite, the listener will not be willing to engage with the speaker's meaning. The higher-level explicature (the propositional attitude) is not linguistically encoded. Understanding the relevance of the underlined utterance in (21) requires the recovery of a higher-level explicature, and not the basic explicature (expressed proposition), on the part of the listener. The encoded linguistic content in (21) plays a part in deriving the implicit meaning instead of revealing the explicit communication.

The degree of explicitness in expressing attitudes differs according to the speaker's relationship with the listener. For instance, in a request by a student to a professor, who has the authority to grade the students' academic 
performance, politeness is bound to be more linguistically encoded than usual. Thus, to achieve optimal relevance, the listener in (21) has enriched the linguistically encoded part in a more elaborate manner. A Korean listener who has access to the assumption in (23) may construct A's meaning as in (25a) but not (25b):

a. The speaker says that she doesn't know if some other students have made the same request as the one she is about to make, or if she's the first student to do so. She then says that she doesn't know how the professor would feel about her request but she politely requests the professor to allow her to shoot the film in her parents' neighborhood.

b. The speaker is asking the professor if some other students have made the same request as the one she is about to make, or if she's the first student to do so. She then says that she doesn't know how the professor would feel about her request but she requests the professor to allow her to shoot the film in her parents' neighborhood.

These assumptions reflect the speaker's efforts at producing utterance and understanding the metapragmatic use of the target language. Accordingly, the listener elaborates what the speaker says (Note 18). That is, (25a) is metapragmatically derived from the perspective of politeness in the Korean culture, which influences speaking styles and plays a role in determining the appropriate use of language. The assumption in (25a) is not necessarily recovered by the professor in (21), but can be derived by a Korean listener who derived this meaning metapragmatically, as in (23).

From the perspective of construction, some listeners prefer brevity and try to use fewer words. They may regard the underlined utterance of (21) as unnecessary. When recovering the higher-level explicature, they may enrich the linguistically encoded logical form as \{THE SPEAKER UNNECESSARILY SAYS P\}, and not \{THE SPEAKER POLITELY SAYS P $\}$. In other words, if the listener is lacking the assumption in (23), he or she may inaccurately identify (25b) as the speaker's intended meaning behind (21), exhibiting an example of the difficulties faced in deriving the intended meaning.

\section{Conclusion}

I have explained that in some casual conversations in English, recovering the speaker's meaning requires an understanding of the speaker's purpose or intention, and failing to comprehend this purpose can lead to difficulties in deriving the speaker's meaning. The paper shows how the explicit meaning of an utterance can be constructed differently by a listener who lacks metapragmatic awareness or one who has a different level of metapragmatic awareness of the target language. I have discussed this finding at an interpersonal level (I call this metapragmatic enrichment), in the form of repairing and elaborating, as techniques to recover higher-level explicatures. This finding highlights the need to be aware of the use of language in the target language, beyond linguistic ability, thus imposing a conscious and perceptive burden on nonnative listeners and leading to difficulties in recovering the speaker's meaning. Although my focus has been on the derivation of explicature by Korean listeners, I hope that these findings will help us understand the subtle differences in enriching linguistically encoded logical form of an utterance between two cultures.

\section{References}

Bach, Kent. (1994). Conversational implicature. Mind and Language, 9, 124-162. http://dx.doi.org/10.1111/j.1468-0017.1994.tb00220.x

Blackemore, Diane. (1992). Understanding utterances: An introduction to pragmatics. Oxford: Blackwell.

Blum-Kulka, Shoshana, Juliane House, \& Gabriele Kasper. (eds.) (1989). Cross-cultural pragmatics: Requests and apologies. Norwood, NJ: Ablex.

Carston, Robyn. (1988). Implicature, explicature and truth-theoretic semantics. In R. Kempson (Ed.), Mental representations: The interface between language and reality (pp. 155-181). Cambridge: Cambridge University Press.

Carston, Robyn. (1997). Enrichment and loosening: complementary processes in deriving the proposition expressed? Linguistische Berichte 8 (Special Issue on Pragmatics), 103-127.

Carston, Robyn. (2002). Utterance and thoughts: The explicit communication. Oxford: Blackwell. http://dx.doi.org/10.1002/9780470754603

Carston, Robyn. (2004). Explicature and semantics. In Davis S, Gillon B (Ed.), Semantics: A Reader (pp. 817-845). Oxford: Oxford University Press. 
Cook, Jiyon, \& Lee, Sungbom. (2007). A pragmatic approach to the explicit content of 'what is said: The need to explicature. Discourse and Cognition, 14, 1-25.

David, Cho. (2009). Hackers TOEFL listening. Seoul: Hackerseohakyeonguso.

Grice, Paul. (1975). Logic and conversation. Syntax and semantics vol. 3, Speech acts, ed. by Peter Cole and Jerry Morgan, 41-58. New York: Academic Press.

Gumperz, John. (1982). Discourse strategies. Cambridge: Cambridge University Press. http://dx.doi.org/10.1017/CBO9780511611834

Horn, Lorence. (1989). A natural history of negation. Chicago: University of Chicago Press.

Lee, Sungbom. (2004). Specification of underdetermined informational contents in verbal communication. Korean Journal of Linguistics, 29, 377-417.

Lee, Sungbom. (2007). Metapragmatics of speech and its interactions with pragmatic inferences. Discourse and Cognition, 14, 117-136.

Levinson, Stephen. (1983). Pragmatics. Cambridge: Cambridge Unviersity Press.

Levinson, Stephen. (2000). Presumptive meanings: The theory of generalized conversational implicature. Cambrige, MA: MIT Press.

Lucy, John. (2004). Reflexive language: Reported speech and metapragmatics. Cambridge, Cambridge University Press.

Mey, Jacob. (2000). Pragmatics: An introduction. Oxford: Blackwell.

Mok, Jong-Ok. (2005). A Study on Korean Students' English Idiom Processing and Learnability. PhD dissertation, Pusan National University.

Recanati, Francois. (1991). The pragmatics of what is said. In S. David (Ed.), Pragmatics: A reader (pp. 97-120). Oxford: Oxford University Press.

Recanati, Francois. (1993). Direct reference: From language and thought. Oxford: Blackwell.

Recanati, Francois. (1995). The alleged priority of literal interpretation. Cognitive Science, 19, 207-232. http://dx.doi.org/10.1207/s15516709 $\operatorname{cog} 1902 \_2$

Recanati, Francois. (2001). What is said. Syntheses, 128, 75-91. http://dx.doi.org/10.1023/A:1010383405105

Searle, John. (1983). Intentionality. Cambridge: Cambridge University Press.

Sperber, Dan, \& Wilson, Deirdre. (1986/1995). Relevance: Communication and cognition. Oxford, Blackwell.

Travis, Charles. (1985). On what is strictly speaking true. Canadian Journal of Philosophy, 15, 187-229.

Verschueren, Jef. (1999). Understanding pragmatics. London: Arnold.

Wilson, Deirdre, \& Sperber, Dan. (1993). Linguistic form and relevance. Lingua, 90, 1-25. http://dx.doi.org/10.1016/0024-3841(93)90058-5

Wilson, Deirdre, \& Sperber, Dan. (2002). Truthfulness and relevance. Mind, 111, 583-632. http://dx.doi.org/10.1093/mind/111.443.583

Wilson, Deirdre, \& Sperber, Dan. (2004). Relevance theory. In G. Ward \& L. Horn (Eds.), The handbook of pragmatics (pp. 607-632). Oxford: Blackwell. http://dx.doi.org/10.1002/9780470756959.ch27

\section{Notes}

Note 1. The experiment was intended to test whether the English sentence "You're kidding" is understandable and what are its interpretations. A total of 40 fourth-year students, native speakers of Korean, at Sejong University participated in this experiment. There were 28 men and 12 women and the subjects were in their twenties (oldest: 27; youngest 22). Two questions were provided in the questionnaire.

A: We'll have to charge you for this service.

B: You're kidding.

Question 1: What does the speaker B mean?

Question 2: How do you feel if you hear the expression "You're kidding"?

Regarding question (1), answer choices were provided and students chose one of the following: 
a. You're not serious.

b. You're lying.

c. Speaker B indicates his dismay.

d. Speaker B suggests that he doesn't believe speaker A.

e. Speaker B emphasizes his confusion.

f. Speaker B indicates that he is amused by the situation.

Of the responders, $80 \%$ chose (a); 7.5\%, (f); 7.5\%, (d); 5\%, (b).

Regarding question (2), students were not given answer options, but were asked to write their answers briefly. Of the students, $40 \%$ responded with "I feel unpleasant"; 25\%, "I feel embarrassed"; 7.5\%, "I feel angry"; 7.5\%, "I feel the speaker ignores me"; 7.5\% did not write anything; 5\% responded with " just so so"; $7.5 \%$ cited other reasons.

Note 2. Sperber and Wilson (1986, 1995), Carston (1988, 1997, 2000, 2004). Also see Bach (1994), Recanati (1991, 1993), and Travis (1985) to learn more about the role played by free enrichment in utterance understanding.

Note 3. For the underdeterminacy thesis, see relevance theorists, Bach (1994), Recanati (1991, 1993, 1995), Searle (1983), and Travis (1985).

Note 4. Examples (7), (9), and (21) are taken from Hackers TOEFL Listening (Cho 2009), which deals with conversations revolving around college life.

Note 5. Some sentences present in the original exchange have been omitted from this excerpt.

Note 6. The explicitly communicated meaning (explicature) is indicated in \{\} . The implicitly communicated meaning (implicature) is indicated in $\langle>$. For discussion of the explicit meaning of what is said along the continuum of the speaker's meaning in Korean advertising language within the relevance-theoretic view of utterance understanding, see Cook and Lee (2007).

Note 7. The professor did not immediately answer the question. She answered (11) only after seeing the picture of the bus taken in London.

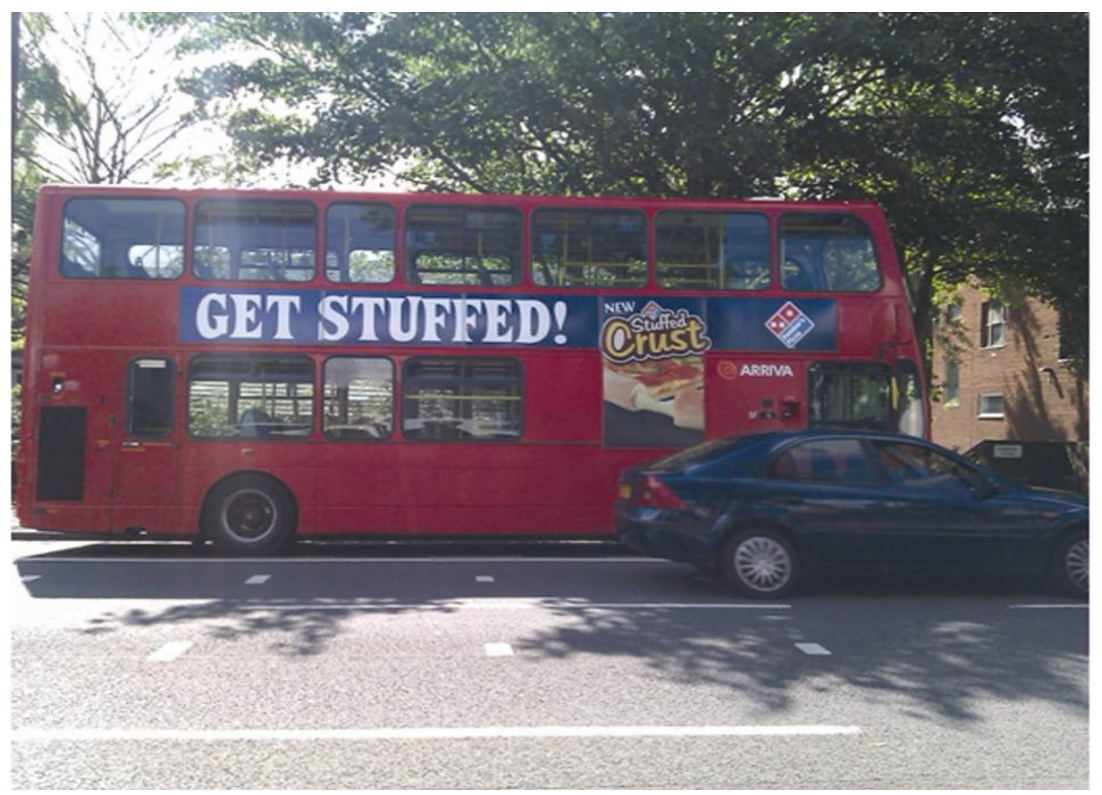

Note 8. Speakers are typically aware of their efforts at conveying meaning and choosing expressions. The metapragmatic level deals with permitting or forbidding the use of language in certain ways. For a discussion of the indicators of metapragmatic awareness, see Verscheren (1999, p. 189-195). For a metapragmatic analysis of language use, see Lucy (2004).

Note 9. If the utterance were produced by a comedian, then the explicature would not be the same. In the case of a comedian, the listener may be inclined to identify (13b) as the explicature, and subsequently (12a), (12b), or (12c) as the intended meaning. 
Note 10. While the pragmatic processes have clearly explained how the communicated proposition (the italicized part) is derived (reference assignment, disambiguation, saturation, enrichment, ad-hoc concept construction) (Sperber and Wilson 1995; Carston 1988, 1997, 2002, 2004; Wilson and Sperber 2002), the process of recovering a communicated attitude is not discussed in detail.

Note 11. For a cultural pragmatic discussion on linguistic behavior (speech act), see Blum-Kulka (1989). The work discusses linguistic expressions and the social meanings carried by their use within and across cultures.

Note 12. See Lee (2004) for an explanation of the difference between semantic enrichment and pragmatic enrichment.

Note 13. Mok (2005) analyzes the two popular English textbooks that have been used in many high schools in Korea. He claims that English textbooks must contain a greater number and variety of English idioms and that systematic teaching and learning of idioms should be a part of English education in Korea.

Note 14. According to Lee's (2004) parallel processing model for the interpretation of an utterance, before processing an utterance, the listener examines what Lee refers to as the "pre-condition." This leads the listener to choose a specific processing path for arriving at the speaker's meaning. Any listener, with or without metapragmatic awareness, can choose a path and finally arrive at an interpretation. This aspect will be discussed further in future works.

Note 15. Furthermore, the listener who can manipulate the language can respond in a totally unexpected way:

(1) A (American): You are kidding.

B (Korean): No, I'm adulting.

(1B) was produced by a Korean student studying English as a foreign language. He makes use of his semantic knowledge (the opposite of the word of "kid" is "adult") and morphological knowledge (adding "ing" to a noun instead of verb) to produce a humorous effect. A response such as (1B) is the result of a different interpretation by a Korean student studying English as a foreign language. He makes use of his semantic knowledge and its function in the interpersonal relationship. If a listener focuses on the propositional meaning, (1B) sounds ridiculous. However, if the listener focuses on why the speaker is uttering it, he or she may find the response humorous.

Note 16. Verschueren (1999, p. 76) argues that context consists of utterers, interpreters, mental worlds, social worlds, and physical worlds, and that each world is not clearly separated. In the case where the utterer's context and the interpreter's context do not overlap, inferring of a common proposition is not guaranteed.

Note 17. This assumption is triggered by the metapragmatic principle proposed by Lee (2007, p. 123): “A speaker may intend that her intentions are recognized by a hearer to minimize risk in communication or to arouse a particular emotion in the hearer." For discussion of the interaction of metapragmatic inference and pragmatic inference, see Lee (2007).

Note 18. The ability to enrich linguistically encoded logical form is not fixed, but can be developed through metapragmatic awareness. If the listener cares about the speaker, is a generous listener, or a defendant of the speaker (i.e., has to report what is said), then they are more likely to make a conscious effort to enrich the linguistic encoding element. This will achieve optimal relevance in the interpersonal relationship. 